\title{
Cyatheales (Polypodiopsida) do Corredor de Biodiversidade do Norte do Pará, Brasil ${ }^{1}$
}

\author{
Luiz Armando de Araújo Góes-Neto ${ }^{2,4}$ e Marcio Roberto Pietrobom ${ }^{3}$
}

Recebido: 19.04.2013; aceito: 17.02.2014

\begin{abstract}
Cyatheales (Polypodiopsida) from the Corredor de Biodiversidade do Norte do Pará, Brazil). This paper is part of a series where the lycophyte and fern species of the Biodiversity Corridor ofnorthern Pará State are presented, produced under the project "Diagnóstico da Biodiversidade das Unidades de ConservaçãoEstaduais do Mosaico Calha Norte, Estado do Pará". In this manuscript the taxonomic treatment of Cyatheales is presented with identification keys, illustrations, distribution, descriptions, and comments to the studied taxa. Two families (Cyatheaceae and Metaxyaceae), three genera (Cnemidaria, Cyathea, and Metaxya), eight species, and one variety are registered. Cyathea is the most representative genus with seven species.
\end{abstract}

Keywords: Amazonia, Cyatheaceae, Guiana Endemism Center, Metaxyaceae

RESUMO - (Cyatheales (Polypodiopsida) do Corredor de Biodiversidade do Norte do Pará, Brasil). Este artigo é parte de uma série onde são apresentadas as espécies de licófitas e samambaias do Corredor de Biodiversidade do Norte do Estado do Pará e faz parte do projeto "Diagnóstico da Biodiversidade das Unidades de Conservação Estaduais do Mosaico Calha Norte, Estado do Pará". Neste manuscrito é apresentado o tratamento taxonômico de Cyatheales com chaves de identificação, ilustrações, distribuição geográfica, descrições e comentários dos táxons estudados. Foram registradas duas famílias (Cyatheaceae e Metaxyaceae), três gêneros (Cnemidaria, Cyathea e Metaxya), oito espécies e uma variedade, sendo o gênero Cyathea o mais representativo com sete espécies.

Palavras-chave: Amazônia, Centro de Endemismo Guiana, Cyatheaceae, Metaxyaceae

\section{Introdução}

Cyatheales pertence à classe Polypodiopsida, é formada por oito famílias e cerca de 665 espécies, distribuídas no oeste e sudeste da Europa, Ásia, Malásia, Australásia, Havaí e nas Américas, com a maioria das espécies ocorrendo nos trópicos (Smith et al. 2006). É um grupo que não possui morfologia característica bem definida, com espécies apresentando caule ereto e robusto como "tronco", enquanto outras apresentam rizoma reptante; algumas possuem apenas tricomas no caule e lâmina, enquanto outras possuem escamas; soros nas posições abaxiais ou marginais, com ou sem indúsio; esporos globosos ou tetraédricoglobosos, trilete (Smith et al. 2006).
Cyatheaceae Kaulf. é uma das famílias com delimitação genérica bastante controversa. Christensen (1905-1906) adotou uma circunscrição claramente artificial baseada na presença/ausência e forma do indúsio, reconhecendo assim três gêneros (Cyathea, Hemitelia e Alsophila); Holttum \& Sen (1961) reconheceram dois gêneros (Cyathea e Cnemidaria), baseados na morfologia das escamas da base do pecíolo; Holttum (1963) considerou um único gênero (Cyathea), com dois subgêneros (Sphaeropteris e Cyathea), baseado nos tipos de indúsio; Tryon (1970) adotou seis gêneros (Sphaeropteris, Alsophila, Nephelea, Trichipteris, Cyathea e Cnemidaria), os quais foram considerados distintos pelas características das escamas, presença e ausência de indúsio e tipo de venação.

1. Parte da Dissertação de Mestrado do primeiro Autor

2. Universidade Federal de Minas Gerais, Instituto de Ciências Biológicas, Avenida Antônio Carlos 6627, 31270-901 Pampulha, Belo Horizonte, MG, Brasil

3. Universidade Federal do Pará, Campus de Bragança, Instituto de Estudos Costeiros, Alameda Leandro Ribeiro s/n, 68370-000 Aldeia, Bragança, PA, Brasil

4. Autor para correspondência: lgoes-neto@hotmail.com 
Alguns anos mais tarde, Lellinger (1987) propôs uma nova circunscrição, onde reconheceu quatro gêneros: Sphaeropteris, Alsophila (incluindo Nephelea), Cyathea (incluindo Trichipteris) e Cnemidaria. Mais recentemente, com base em estudos moleculares, Smith et al. (2006) reconheceram cinco gêneros: Alsophila (incluindo Nephelea), Cyathea (incluindo Cnemidaria, Hemitelia, Trichipteris), Gymnosphaera, Hymenophyllopsis e Sphaeropteris (incluindo Fourniera).

Metaxyaceae Pic. Serm. é outra família pertencente à ordem Cyatheales, que não apresenta problemas em sua delimitação uma vez que é monogenérica e possui seu monofiletismo bem suportado (Smith et al. 2006). Metaxyaceae distingue-se das demais samambaias arborescentes em diversos aspectos, dentre estes, por possuir indumento do rizoma e pecíolo formado apenas por tricomas, sistema vascular do tipo sifonostelo anfiflóico (Lucansky 1974), esporos quase esféricos com uma camada de perina (Gastony \& Tryon 1976) e por não possuir uma bainha associada ao cilindro vascular do caule (Lucansky 1974, 1982).

Dentre os principais estudos florísticos realizados com samambaias na Amazônia Brasileira, destaca-se o de Tryon \& Conant (1975), onde os autores registraram 11 espécies pertencentes à ordem Cyatheales, das quais, quatro (Cyathea cyatheoides, C. hirsuta, C. microdonta e Metaxya rostrata) ocorreram no Estado do Pará. De acordo com os estudos mais recentes (i.e. Rodrigues et al. 2004, Costa et al. 2006, Costa \& Pietrobom 2007, Maciel et al. 2007, Costa \& Pietrobom 2010 e Fernandes et al. 2012) seis espécies de Cyatheales eram conhecidas no Estado do Pará.

Este estudo é parte do projeto "Diagnóstico da Biodiversidade das Unidades de Conservação Estaduais do Mosaico Calha Norte, Estado do Pará" e objetivou inventariar as espécies de licófitas e samambaias em cinco Unidades de Conservação no Corredor de Biodiversidade do Norte do Pará. Este manuscrito faz parte de uma série iniciada em GóesNeto \& Pietrobom (2012a), no qual são tratados os representantes das licófitas e samambaias da referida área. No presente artigo são apresentadas chaves de identificação, ilustrações, distribuição geográfica e comentários sobre as espécies da ordem Cyatheales, aumentando o conhecimento sobre tais vegetais na Amazônia Brasileira.

\section{Material e métodos}

As informações sobre a localização e a caracterização geral do Corredor de Biodiversidade do
Norte do Pará (CBNP), estão disponíveis em Funk et al. (2007), Rossetti \& Toledo (2007), Avila-Pires et al. (2010) e Aleixo et al. (2011).

A metodologia utilizada na coleta, herborização e descrição do material estudado encontra-se em GóesNeto \& Pietrobom (2012a).

A terminologia utilizada nas descrições das espécies está de acordo com Lellinger (2002), os nomes dos autores dos táxons estão abreviados de acordo com Pichi Sermolli (1996).

Os espécimes selecionados estão depositados no herbário MG, com suas duplicatas doadas ao herbário STU. Os acrônimos dos herbários seguem Thiers (2013).

Korall et al. (2006) comentaram sobre a necessidade de uma nova classificação para Cyatheaceae, contudo, acreditam que uma abordagem mais conservadora, com o mínimo de alterações possíveis, seria favorável. Desta forma, foi adotada uma posição mais conservadora quanto à delimitação genérica para a família Cyatheaceae, seguindo-se Lellinger (1987); já para Metaxyaceae, seguiu-se Smith et al. (2006).

A representatividade das famílias no Brasil, bem como a distribuição geográfica das espécies no país, está baseada em Windisch \& Santiago (2013) para Cyatheaceae, e Sylvestre (2013) para Metaxyaceae e, quando necessário, estas foram complementadas por outra bibliografia.

\section{Resultados e Discussão}

Foram registradas no CBNP duas famílias (Cyatheaceae e Metaxyaceae), três gêneros (Cnemidaria, Cyathea e Metaxya), oito espécies e uma variedade, sendo Cyathea o gênero mais representativo, com sete espécies.

Chave de identificação para as famílias de Cyatheales do CBNP

1. Plantas geralmente arborescentes; pecíolo somente com escamas ou com escamas e tricomas; pinas laterais 1-2-pinada; pina apical pinatífida a 1-pinada . Cyatheaceae

1. Plantas herbáceas; pecíolo somente com tricomas; pinas laterais inteiras; pina apical conforme Metaxyaceae

Cyatheaceae Kaulf., Wesen Farrenkr. 119. 1827.

A família é monofilética, possui quatro gêneros (Alsophila R. Br., Cnemidaria C. Presl, Cyathea Sm. e Sphaeropteris Bernh.) (Lellinger 1987) e mais de 600 espécies (Smith et al. 2006) com distribuição 
pantropical (Lehnert 2011). No Brasil são conhecidas 41 espécies (Windisch \& Santiago 2013).

Chave de identificação para os gêneros de Cyatheaceae do CBNP

1. Lâmina 1-pinada a 1-pinado-pinatífida; tricomas ausentes na costa e cóstula ...... Cnemidaria

1. Lâmina 2-3-pinada; tricomas presentes na costa e cóstula ..... Cyathea

Cnemidaria C. Presl, Tent. Pterid. 56. 1836.

O gênero possui cerca de 27 espécies com distribuição neotropical (Moran 1995). No Brasil são conhecidas Cnemidaria uleana (Samp.) R.M. Tryon e a espécie recentemente registrada $C$. spectabilis (Kunze) R.M. Tryon (Góes-Neto \& Pietrobom 2012b).

Cnemidaria spectabilis (Kunze) R.M. Tryon var. spectabilis, Contr. Gray Herb. 200: 52. 1970.

Figuras 1-4

Planta terrestre, subarborescente. Caule ereto, escamas bicolores com o centro marrom escuro e margens estreitamente esbranquiçadas. Lâmina 1-pinada a 1-pinado-pinatífida, pinas pinatífidas com o enseio estendendo-se até no máximo $1 / 3$ do segmento entre a margem e a costa, glabra em ambas as faces; pecíolo com espinhos e escamas bicolores (mais abundantes na base), brilhantes, com as margens mais claras e normalmente laceradas; raque com espinhos. Venação parcialmente livre, furcada, com os pares de vênulas basais adjacentes formando aréolas costais. Soros globosos dispostos quase sempre em uma fileira entre a margem e a costa; paráfises rudimentares ou ausentes; indúsio membranáceo, aderido ao receptáculo em apenas um dos lados, ciliado.
Material selecionado: BRASIL. PARÁ: Oriximiná, Estação Ecológica do Grão-Pará, Serra do Acarí, 30-VIII-2008, M.R. Pietrobom \& S. Maciel 7858(MG).

A espécie possui registros em Trinidad e Tobago, Venezuela, Guiana, Suriname, Guiana Francesa (Stolze 1974) e Brasil (PA) (Windisch \& Santiago 2013). Na área foi coletada como terrícola em floresta submontana aberta de terra firme, próximo a um igarapé, entre 470-500 $\mathrm{m}$ de altitude.

Além dos caracteres descritos na chave, Cnemidaria spectabilis diferencia-se das demais Cyatheaceae da área pela venação parcialmente livre, furcada, com os pares de vênulas basais adjacentes formando aréolas costais. De acordo com Stolze (1974), a variedade spectabilis possui o pecíolo com poucas ou nenhuma escama, com exceção da base, que sempre as possui. C. spectabilis distingue-se de C. uleana por possuir as pinas (exceto o par basal e os pares distais) inteiras a pinatífidas com o enseio estendendo-se até no máximo a metade do segmento entre a margem e a costa, enquanto que C. uleana possui as pinas (exceto o par basal e os pares distais) profundamente pinatífidas com o enseio estendendo-se além da metade do segmento entre a margem e a costa (Stolze 1974). Além disso, os soros em C. uleana podem apresentar-se comumente em duas fileiras, enquanto que em C. spectabilis os soros estão dispostos quase sempre em uma linha entre a margem e a costa (figura 2).

Cyathea Sm., Mém. Acad. Roy. Sci. (Turin) 5:416. 1793.

O gênero possui cerca de 115 espécies pantropicais, sendo a maioria neotropical (Smith 1995, Mickel \& Smith 2004). No Brasil são conhecidas cerca de 33 espécies (Windisch \& Santiago 2013).

Chave de identificação para as espécies de Cyathea do CBNP

1. Soros indusiados

2. Escamas do caule bicolores

2. C. macrosora

2. Escamas do caule monocromáticas

3. Face abaxial do tecido laminar glabra, costa e cóstula glabras a esparsamente ciliadas; margem do indúsio glabra a esparsamente ciliada 1. C. cyatheoides

3. Face abaxial do tecido laminar com tricomas, costa e cóstula densamente ciliadas; margem do indúsio densamente ciliada.... 7. C. surinamensis

1. Soros sem indúsios

4. Pecíolo e raque sem espinhos 3. C. marginalis

4. Pecíolo e raque com espinhos

5. Pinas reduzindo-se em direção ao ápice e à base 5. C. oblonga

5. Pinas reduzindo-se apenas em direção ao ápice

6. Escamas do caule bicolores; costa sem espinhos 6. C. pungens

6. Escamas do caule monocromáticas; costa com espinhos 4. C. microdonta 
1. Cyathea cyatheoides (Desv.) K.U. Kramer, The Pteridophytes of Suriname 39. 1978.

Planta terrestre, arborescente. Caule com escamas monocromáticas, marrons e brilhantes. Lâmina 2-pinado-pinatífida, pinas reduzindo-se em direção ao ápice, não ou pouco reduzidas em direção à base; pínula pinatífida; face adaxial do tecido laminar glabra, tricomas sobre a costa e cóstula; face abaxial do tecido laminar glabra, costa e cóstula glabros a esparsamente ciliados; pecíolo com a base muricada, com escamas; raque e costa inermes. Venação livre. Soros globosos; paráfises normalmente mais curtas que o esporângio; indúsio glabro a esparsamente ciliado.

Material selecionado: BRASIL. PARÁ: Almeirim, Reserva Biológica do Maicuru, 25-X-2008, S. Maciel 1214 (MG, STU). Na área foi coletada como terrícola em floresta ombrófila de terra firme, entre 250-490 m de altitude.
A espécie possui registros na Venezuela, Guiana, Suriname, Guiana Francesa (Large \& Braggins 2004) e Brasil (AM, AP, PA, RR) (Windisch 1978).

Cyathea cyatheoides assemelha-se à $C$. hirsuta C. Presl (espécie que ocorre no sudeste e sul do Brasil). Podem ser distinguidas por $C$. cyatheoides possuir a lâmina glabra e margem do indúsio glabra a esparsamente ciliada, enquanto que $C$. hirsuta possui lâmina com tricomas e margem do indúsio sempre ciliada.

2. Cyathea macrosora (Baker ex Thurn) Domin, Pteridophyta 263. 1929.

Planta terrestre, arborescente. Caule com escamas bicolores, com o centro marrom e as margens mais claras. Lâmina 2-pinado-pinatífida, pinas reduzindo-se em direção ao ápice, não ou pouco reduzidas em direção à base; pínula pinatífida; face adaxial do tecido laminar glabra, tricomas sobre a costa e cóstula; face abaxial do tecido laminar glabra, costa e cóstula

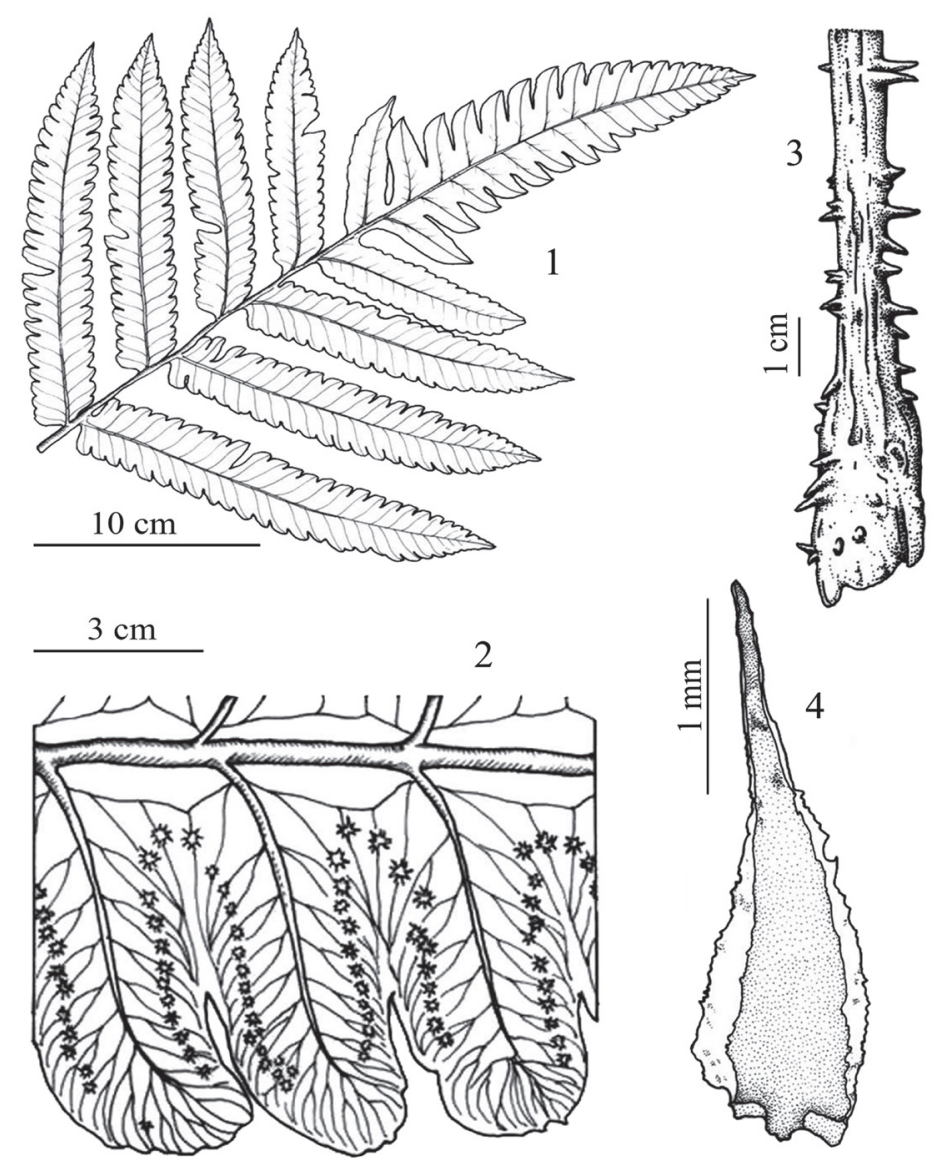

Figuras 1-4. Cnemidaria spectabilis (Kunze) R.M. Tryon var. spectabilis 1. Parte apical da lâmina. 2. Detalhe da venação. 3. Base do pecíolo. 4. Escama da base do pecíolo (M.R. Pietrobom \& S. Maciel 7858).

Figures 1-4. Cnemidaria spectabilis (Kunze) R.M. Tryon var. spectabilis 1. Apical part of blade. 2. Detail of veins. 3. Petiole basis. 4. Scale from petiole basis (M.R. Pietrobom \& S. Maciel 7858). 
glabros a esparsamente ciliados; pecíolo muricado, com escamas; raque e costa inermes. Venação livre. Soros globosos; paráfises mais longas que os esporângios; indúsio glabro a esparsamente ciliado.

Material selecionado: BRASIL. PARÁ: Oriximiná, Estação Ecológica do Grão-Pará, Serra do Acarí, 31-VIII-2008, M.R. Pietrobom \& S. Maciel 7958 (MG, STU). Na área foi coletada como terrícola em floresta de terra firme montana, ca. $330 \mathrm{~m}$ de altitude, e como epífita (acidental) em floresta ombrófila aberta, ca. $600 \mathrm{~m}$ de altitude.

A espécie possui registros na Costa Rica, Colômbia, Venezuela, Guiana (Large \& Braggins 2004) e Brasil (AM, PA, RO, RR) (Windisch \& Santiago 2013).

Cyathea macrosora assemelha-se à C. macrocarpa (C. Presl) Domin, sendo as escamas do caule e da base do pecíolo e o tamanho do peciólulo das pínulas basais, as principais diferenças. Em C. macrosora as escamas são bicolores e o peciólulo diminui gradativamente em direção ao ápice, já em C. macrocarpa, as escamas são monocromáticas (esbranquiçadas a paleáceas) e o peciólulo é curto desde a base. Segundo Windisch (1978), C. macrosora possui formas variáveis e junto com Cyathea rufescens (Kuhn) Windisch, que ocorre no Peru, forma um subgrupo caracterizado pelas escamas bicolores e ausência de uma pina apical distinta.

3. Cyathea marginalis (Klotzsch) Domin, Pteridophyta 263. 1929.

Planta terrestre, arborescente. Caule com escamas monocromáticas, esbranquiçadas a paleáceas. Lâmina 2-pinada, pinas reduzindo-se em direção ao ápice, não ou pouco reduzidas em direção à base; pínula pinatífida; face adaxial do tecido laminar glabra, costa e cóstula glabros; face abaxial do tecido laminar glabra, costa e cóstula glabros; pecíolo inerme, com escamas; raque e costa inermes. Venação livre. Soros globosos; paráfises mais longas que os esporângios; indúsio ausente.

Material selecionado: BRASIL. PARÁ: Oriximiná, Estação Ecológica do Grão-Pará, Serra do Acarí, 27-VIII-2008, S. Maciel \& M.R. Pietrobom 789 (MG, STU).

A espécie possui registros na Venezuela, Guiana, Suriname, Guiana Francesa (Funk et al. 2007) e Brasil (PA) (Sampaio 1930). Na área foi coletada como terrícola em floresta de terra firme montana, na margem de um igarapé, 400-600 m de altitude.
Dentre todas as espécies de Cyathea registradas no CBNP, Cyathea marginalis é a única que possui os eixos completamente inermes. Caracteriza-se pelas escamas do caule esbranquiçadas, eixos sem espinhos, paráfises maiores que os esporângios e ápice das pinas pinatífido.

\section{Cyathea microdonta (Desv.) Domin, Pteridophyta} 263. 1929.

Planta terrestre, arborescente. Caule com escamas monocromáticas, marrons e mate. Lâmina 2-pinadopinatífida a 3-pinada, pinas reduzindo-se em direção ao ápice, não reduzidas em direção à base; pínula pinatífida; face adaxial do tecido laminar glabra, tricomas sobre a costa e cóstula; face abaxial do tecido laminar glabra, costa e cóstula esparsamente ciliados; pecíolo espinescente, com escamas; raque e costa espinescentes. Venação livre. Soros globosos; paráfises mais curtas que os esporângios; indúsio ausente.

Material selecionado: BRASIL. PARÁ: Óbidos, Estação Ecológica do Grão-Pará, 21-I-2009, M.G.C. Souza \& G. Teixeira 432 (MG, STU).

A espécie possui registros no México, América Central, Grandes Antilhas, Colômbia, Venezuela, Guiana, Suriname, Guiana Francesa, Equador, Peru, Bolívia (Mickel \& Smith 2004) e Brasil (AC, AM, AP, BA, CE, ES, GO, MG, MT, PA, PB, PE, PI, RJ, RO, RR, SP, TO) (Windisch \& Santiago 2013). Na área foi coletada como terrícola em floresta ombrófila de terra firme, próximo a um igapó, ca. $230 \mathrm{~m}$ de altitude.

Cyathea microdonta caracteriza-se por possuir pecíolo, raque e costa com espinhos, eixos em ambas as faces da lâmina cobertos por pequenos tricomídios e soros sem indúsios. Apesar de possuir as escamas do caule monocromáticas, foi observado em quase todos os espécimes que as margens desta estrutura possuem textura mais membranácea e coloração mais clara, com as células marginais organizadas distintamente das células centrais, dando um aspecto característico às escamas.

\section{Cyathea oblonga (Klotzsch) Domin, Pteridophyta} 263. 1929.

Planta terrestre ou rupícola, arborescente. Caule com escamas bicolores, com o centro marrom e as margens mais claras. Lâmina 2-pinado-pinatífida, pinas reduzindo-se em direção ao ápice e à base; pínula pinatífida; face adaxial do tecido laminar glabra, tricomas sobre a costa e cóstula; face abaxial 
do tecido laminar glabra, costa e cóstula esparsamente ciliados; pecíolo espinescente, com escamas; raque espinescente (exceto na porção distal), costa inerme. Venação livre. Soros globosos; paráfises mais curtas que os esporângios; indúsio ausente.

Material selecionado: BRASIL. PARÁ: Oriximiná, Estação Ecológica do Grão-Pará, Serra do Acarí, 30-VIII-2008, S. Maciel \& M.R. Pietrobom 983 (MG, STU).

A espécie possui registros na Venezuela, Guiana, Bolívia, sul dos Andes e Brasil (AP, GO, MT, PA, RR) (Holttum \& Edwards 1982, Edwards 1998). Na área foi coletada como rupícola em floresta ombrófila aberta e como terrestre em floresta montana, geralmente associada a cursos d'água, entre $140-500 \mathrm{~m}$ de altitude.

De acordo com Windisch \& Santiago (2013), Cyathea oblonga é sinônimo heterotípico de C. pungens; entretanto, segundo M. Lehnert (com. pess.), as espécies C. oblonga e C. pungens são morfologicamente distintas e não devem ser tratadas como sinônimos. Kramer (1978) reconheceu ambas as espécies e as distinguiu por C. oblonga possuir pínulas glabras abaxialmente, estreitando-se abruptamente até o ápice agudo, enquanto que em $C$. pungens as pínulas possuem tricomas na face abaxial e estreitamse gradualmente até o ápice acuminado. Não obstante, Holttum \& Edwards (1982) comentaram que alguns espécimes de C. oblonga oriundos do Monte Roraima (região próxima à área estudada) apresentam tricomas na face abaxial da costa e cóstula, assim como constatado neste estudo.

Além das características supracitadas, todos os espécimes de $C$. oblonga examinados no presente estudo possuem uma conspícua redução das pinas em direção à base (ausente em C. pungens), além disso, possuem a raque sempre com espinhos (exceto na porção distal), caráter que nem sempre está presente na raque de $C$. pungens. Desta forma, após a observação de diversos exemplares destas duas espécies, ficou evidente tratar-se de plantas morfologicamente distintas, e por este motivo, ambas foram reconhecidas.

6. Cyathea pungens (Willd.) Domin, Pteridophyta 263. 1929.

Planta terrestre ou rupícola, arborescente. Caule com escamas bicolores com o centro marrom e as margens mais claras. Lâmina 2-pinado-pinatífida, pinas reduzindo-se em direção ao ápice, não reduzidas em direção à base; pínula pinatífida; face adaxial do tecido laminar glabra, tricomas sobre a costa e cóstula; face abaxial do tecido laminar com tricomas rudimentares, costa e cóstula esparsamente ciliados; pecíolo espinescente, com escamas; raque espinescente ou inerme, costa inerme. Venação livre. Soros globosos; paráfises mais curtas que os esporângios; indúsio ausente.

Material selecionado: BRASIL. PARÁ: Alenquer/ Monte Alegre, Floresta Estadual do Trombetas, 24-IV-2009, S. Maciel 723 (MG, STU).

A espécie possui registros na República Dominicana, Antilhas, Trinidad e Tobago, Colômbia, Venezuela, Guiana, Suriname, Guiana Francesa, Equador, Peru, Bolívia (Lehnert 2006) e Brasil (AC, AM, BA, CE, GO, MS, MT, PA, PB, PE, PR, RO, SP) (Windisch \& Santiago 2013). Na área foi coletada como terrícola em floresta submontana densa e como terrícola e rupícola em floresta ombrófila aberta, próximo a um igarapé, ca. 500-600 m de altitude.

Esta é uma espécie que possui grande plasticidade morfológica. Dentre os espécimes estudados, observou-se uma ampla variação na presença/ausência e tamanho dos espinhos da raque. Pietrobom \& Barros (2006) caracterizaram Cyathea pungens pela lâmina com pina apical subconforme, soros supramedianos e paráfises geralmente decíduas, mais curtas ou iguais aos esporângios.

\section{Cyathea surinamensis (Miq.) Domin, Pteridophyta} 264. 1929.

Planta terrestre, arborescente. Caule com escamas monocromáticas, marrons e brilhantes. Lâmina 2-pinado-pinatífida, pinas reduzindo-se em direção ao ápice, não ou pouco reduzidas em direção à base; pínula pinatífida; face adaxial do tecido laminar com tricomas, tricomas sobre a costa e cóstula; face abaxial do tecido laminar com tricomas, costa e cóstula densamente ciliados; pecíolo com a base muricada, com escamas; raque e costa inermes. Venação livre. Soros globosos; paráfises mais curtas que os esporângios; indúsio densamente ciliado.

Material selecionado: BRASIL. PARÁ: Oriximiná, Estação Ecológica do Grão-Pará, Serra do Acarí, 28-VIII-2008, M.R. Pietrobom \& S. Maciel 7772 (MG, STU).

A espécie possui registros em Trinidad e Tobago, Venezuela, Guiana, Suriname, Guiana Francesa (Holttum \& Edwards 1982, Prado \& Freitas 2005) e 
Brasil (AM, AP, PA) (Windisch \& Santiago 2013). Na área foi coletada como terrícola em floresta de terra firme aberta e montana, geralmente às margens de um igarapé, 220-600 $\mathrm{m}$ de altitude.

Cyathea surinamensis assemelha-se à C. cyatheoides, distinguindo-se por possuir tricomas grandes, robustos e em maior quantidade, tanto nos eixos quanto na margem do indúsio, enquanto que C. cyatheoides possui os tricomas dos eixos e do indúsio curtos, delicados e em menor quantidade (por vezes glabrescente).

Metaxyaceae Pic. Serm., Webbia 24(2): 701. 1970.

A família é monofilética, possui um gênero (Metaxya) e duas espécies que se distribuem desde Chiapas no México até o sul da Bolívia e Brasil (Tryon \& Tryon 1982, Smith et al. 2006).

Metaxya C. Presl, Tent. Pterid. 59. 1836.

O gênero possui duas espécies neotropicais (Smith et al. 2001). No Brasil é conhecida apenas uma espécie (Sylvestre 2013).

Metaxya rostrata (Kunth) C. Pres1, Tent. Pterid. 60, t. 1, f. 5. 1836.

Planta terrestre. Caule longo-reptante com tricomas amarelados a castanho-claros. Lâmina 1-pinada; pecíolo sulcado adaxialmente com tricomas castanho-claros, diminutos e esparsos; pinas cartáceas, lanceoladas, pecioluladas, base assimétrica, cuneada, ápice geralmente caudado, denteado a serreado, glabra em ambas as faces; pina apical conforme; raque sulcada adaxialmente, glabrescente. Venação livre, simples, comumente furcadas. Soros globosos a levemente alongados; paráfises presentes; indúsio ausente.

Material selecionado: BRASIL. PARÁ: Oriximiná, Estação Ecológica do Grão-Pará, 27-VIII-2008, S. Maciel \& M.R. Pietrobom 803 (MG).

A espécie possui registros no México, América Central, Antilhas, Colômbia, Venezuela, Guiana, Suriname, Guiana Francesa, Equador, Peru, Bolívia (Riba 1995) e Brasil (AC, AM, AP, BA, MA, MS, MT, PA, PB, PE, PI, RO, RR, TO) (Dias et al. 2001). Na área foi coletada como terrícola em floresta ombrófila aberta de terra firme, 475-600 $\mathrm{m}$ de altitude, quase sempre às margens de cursos d'água.

O gênero Metaxya foi tido por muito tempo como monoespecífico, porém, Smith et al. (2001) descreveram uma nova espécie (Metaxya lanosa A.R. Sm. \& H. Tuomisto), registrada apenas na Amazônia Venezuelana e Peru, podendo provavelmente também ocorrer na Colômbia e no Brasil. M. rostrata difere de $M$. lanosa por esta última possuir pecíolo e raque densamente cobertos por tricomas ferrugíneos, lâmina com textura coriácea mais espessa, pinas mais amplamente elípticas com margens esbranquiçadas e cartilaginosas e base decurrente, face abaxial com a venação mais proeminente, além de um peciólulo mais longo principalmente na pina apical (Smith et al. 2001).

\section{Agradecimentos}

Agradecemos ao Conselho Nacional de Desenvolvimento Científico e Tecnológico (CNPq), pela bolsa de Mestrado concedida ao primeiro Autor; à Conservação Internacional - Brasil, pelo financiamento do projeto; à Fundação Instituto para o Desenvolvimento da Amazônia, pelo apoio logístico; à Secretaria de Estado de Meio Ambiente - PA, pela concessão da licença para coleta; ao Museu Paraense Emílio Goeldi, pela infraestrutura disponibilizada; ao Dr. Marcus Lehnert, pela determinação de alguns espécimes e pelos comentários sobre o gênero Cyathea; ao ilustrador Carlos Alvarez, pela confecção da prancha.

\section{Literatura citada}

Aleixo, A., Poletto, F., Lima, M.F.C., Castro, M., Portes, E. \& Miranda, L.S. 2011. Notes on the vertebrates of northern Pará, Brazil: a forgotten part of the Guianan Region, II. Avifauna. Boletim do Museu Paraense Emílio Goeldi, Ciências Naturais 6: 11-65.

Avila-Pires, T.C.S., Hoogmoed, M.S. \& Rocha, W.A. 2010. Notes on the vertebrates of northern Pará, Brazil: a forgotten part of the Guianan Region, I. Herpetofauna. Boletim do Museu Paraense Emílio Goeldi, Ciências Naturais 5: 13-112.

Christensen, C.F.A. 1905-1906. Index Filicum. Hagerup, Copenhagen.

Costa, J.M. \& Pietrobom, M.R. 2007. Pteridófitas (Lycophyta e Monilophyta) da Ilha de Mosqueiro, município de Belém, estado do Pará, Brasil. Boletim do Museu Paraense Emílio Goeldi, Ciências Naturais 2: 45-55.

Costa, J.M. \& Pietrobom, M.R. 2010. Samambaias e licófitas do Parque Ecológico do Gunma, município de Santa Bárbara do Pará, estado do Pará, Brasil. Rodriguésia 61: 223-232. 
Costa, J.M., Souza, M.G.C. \& Pietrobom, M.R. 2006. Levantamento florístico das pteridófitas (Lycophyta e Monilophyta) do Parque Ambiental de Belém (Belém, Pará, Brasil). Revista de Biologia Neotropical 3: 4-12.

Dias, E.R.F., Pôrto, K.C., Barros, I.C.L. \& Mariz, G. 2001. New recordings of pteridophytes for the state of Pernambuco, Northeast Brazil. Boletín Ecotrópica, Ecosistemas Tropicales 34: 31-41.

Edwards, P.J. 1998. The pteridophytes of Ilha de Maracá. In: W. Milliken \& J.A. Ratter (eds.). Maracá: the Biodiversity and Enviroment of Amazonian Rainforest. John Wiley \& Sons Ltd, Chicester, pp. 112-129.

Fernandes, R.S., Maciel, S. \& Pietrobom, M.R. 2012. Licófitas e monilófitas das Unidades de Conservação da Usina Hidroelétrica - UHE de Tucuruí, Pará, Brasil. Hoehnea 39: 247-285.

Funk, V.A., Berry, P.E., Alexander, S., Hollowell, T.H. \& Kelloff, C.L. 2007. Checklist of the plants of the Guiana Shield (Venezuela: Amazonas, Bolivar, Delta Amacuro; Guyana, Surinam, French Guiana). Contributions from the United States National Herbarium 55: 1-584.

Gastony, G.J. \& Tryon, R.M. 1976. Spore morphology in the Cyatheaceae. II. The genera Lophosoria, Metaxya, Sphaeropteris, Alsophila, and Nephelea. American Journal of Botany 63: 738-758.

Góes-Neto, L.A.A. \& Pietrobom, M.R. 2012a. Aspleniaceae (Polypodiopsida) do Corredor de Biodiversidade do Norte do Pará, Brasil: um fragmento do Centro de Endemismo Guiana. Acta Botanica Brasilica 26: 456-463.

Góes-Neto, L.A.A. \& Pietrobom, M.R. 2012b. Novos registros de samambaias para a Amazônia Brasileira. Rodriguésia 63: 1151-1155.

Holttum, R.E. 1963. Cyatheaceae. In: C.G.G.J. van Steenis \& R.E. Holttum (eds.). Flora Malesiana II. Botanic Gardens of Indonesia, Lembaga, pp. 65-176.

Holttum, R.E. \& Edwards, P.J. 1982. The tree-ferns of Mount Roraima and neighbouring areas of the Guayana Highlands with comments on the family Cyatheaceae. Kew Bulletin 38: 155-189.

Holttum, R.E. \& Sen, U. 1961. Morphology and classification of the tree fern. Phytomorphology 11: 406-420.

Korall, P., Pryer, K.M., Metzgar, J.S., Schneider, H. \& Conant, D.S. 2006. Tree ferns: Monophyletic groups and their relationships as reveled by four protein-code plastid loci. Molecular Phylogenetics and Evolution 39: 830-845.

Kramer, K.U. 1978. Pteridophytes of Suriname. An enumeration with key of the ferns and ferns-allied. Uitgaven Natuurwetenschappelijke Studiekring voor Suriname en de Nederlandse Antillen 93: 1-198.
Large, M.F. \& Braggins, J.E. 2004. Tree ferns. Timber Press, Cambridge.

Lehnert, M. 2006. The Cyatheaceae and Dicksoniaceae (Pteridophyta) of Bolivia. Brittonia 58: 229-244.

Lehnert, M. 2011. The Cyatheaceae (Polypodiopsida) of Peru. Brittonia 63: 11-45.

Lellinger, D.B. 1987. The disposition of Trichopteris (Cyatheaceae). American Fern Journal 77: 90-94.

Lellinger, D.B. 2002. A modern multilingual Glossary for taxonomic Pteridology. American Fern Society Inc., Washington.

Lucansky, T.W. 1974. Comparative studies of the nodal and vascular anatomy in the neotropical Cyatheaceae. I. Metaxya and Lophosoria. American Journal of Botany 61: 464-471.

Lucansky, T.W. 1982. Anatomical studies of the neotropical Cyatheaceae. II. Metaxya and Lophosoria. American Fern Journal 72: 19-28.

Maciel, S., Souza, M.G.C. \& Pietrobom, M.R. 2007. Licófitas e monilófitas do Bosque Rodrigues Alves Jardim Botânico da Amazônia, município de Belém, estado do Pará, Brasil. Boletim do Museu Paraense Emílio Goeldi, Ciências Naturais 2: 69-83.

Mickel, J.T. \& Smith, A.R. 2004. The Pteridophytes of Mexico. New York Botanical Garden, New York.

Moran, R.C. 1995. Cnemidaria. In: G. Davidse, M. Souza \& S. Knapp (eds.). Flora Mesoamericana. v. 1: Psilotaceae a Salviniaceae. Universidad Nacional Autónoma de México, Ciudad de México, pp. 90-93.

Pichi Sermolli, R.E.G. 1996. Authors of scientific names in Pteridophyta. Royal Botanic Gardens, Kew.

Pietrobom, M.R. \& Barros, I.C.L. 2006. Pteridófitas da Mata do Estado, município de São Vicente Férrer, Estado de Pernambuco, Brasil: Cyatheaceae, Dennstaedtiaceae. Revista de Biologia Neotropical 3: 109-124.

Prado, J. \& Freitas, C.A.A. 2005. Flora da Reserva Ducke, Amazonas, Brasil: Pteridophyta - Cyatheaceae. Rodriguésia 56: 35-37.

Riba, R. 1995. Metaxyaceae. In: G. Davidse, M. Souza \& S. Knapp (eds.). Flora Mesoamericana. v. 1: Psilotaceae a Salviniaceae. Universidad Nacional Autónoma de México, Ciudad de México, pp. 85-86.

Rodrigues, S.T., Almeida, S.S., Andrade, L.H.C., Barros, I.C.L \& van den Berg, M.E. 2004. Composição florística e abundância de pteridófitas em três ambientes da bacia do rio Guamá, Belém, Pará, Brasil. pp. 35-42.

Rossetti, D. \& Toledo, P.M. 2007. Environmental changes in Amazonia as evidenced by geological and paleontological data. Revista Brasileira de Ornitologia 15: 251-264.

Sampaio, A.J. 1930. Eufilicíneas do Rio Cuminá. Arquivos do Museu Nacional 32: 8-60. 
Smith, A.R. 1995. Pteridophytes. In: P.E. Berry, B.K. Holst $\&$ K. Yatskievych (eds.). Flora of the Venezuelan Guyana, v. 2. Pteridophytes, Spermatophytes: AcanthaceaeAraceae. Timber Press, Portland, pp. 1-334.

Smith, A.R., Tuomisto, H., Pryer, K.M., Hunt, J.S. \& Wolf, P.G. 2001. Metaxya lanosa, a second species in the genus and fern family Metaxyaceae. Systematic Botany 26: 480-486.

Smith, A.R., Pryer, K.M., Schuettpelz, E., Korall, P., Schneider, H. \& Wolf, P.G. 2006. A classification for extant ferns. Taxon 55: 705-731.

Stolze, R.G. 1974. A taxonomic revision of the genus Cnemidaria (Cyatheaceae). Fieldiana Botany 37: 1-98.

Sylvestre, L. 2013. Metaxyaceae. In: J. Prado \& L.S. Sylvestre (coords.). Samambaias e licófitas. In: R.C. Forzza, J.F. Baumgratz, C.E. de M. Bicudo, D. Canhos, A.A. Carvalho Jr., A. Costa, D.P. Costa, M. Hopkins, M.P. Leitman, L.G. Lohmann, E.N. Lughadha, L.C. Maia, G. Martinelli, M. Menezes, M.P. Morin, M. Nadruz, A.L. Peixoto, J.R. Pirani, J. Prado, L.P. Queiroz, S. de Souza, V.C. Souza, J.R. Stehmann, L.S. Sylvestre, B.M.T. Walter \& D.C. Zappi (eds.). Lista de Espécies da Flora do Brasil. Disponível em http://floradobrasil. jbrj.gov.br/jabot/floradobrasil/FB91511 (acesso em 28-VII-2013).
Thiers, B. [continuously updated]. Index Herbariorum: A global directory of public herbaria and associated staff. In: New York Botanical Garden's Virtual Herbarium. Disponível em http://sweetgum.nybg.org/ih/ (acesso em 28-VII-2013).

Tryon, R.M. 1970. The classification of the Cyatheaceae. Contributions from the Gray Herbarium 200: 1-53.

Tryon, R.M. \& Conant, D.S. 1975. The ferns of Brazilian Amazonia. Acta Amazonica 5: 23-34.

Tryon, R.M. \& Tryon, A.F. 1982. Ferns and allied plants, with special reference to Tropical America. SpringVerlag, New York.

Windisch, P.G. 1978. Sphaeropteris (Cyatheaceae), the systematic of the group of Sphaeropteris hirsuta. Memoirs of the New York Botanical Garden 29: 2-22.

Windisch, P.G. \& Santiago, A.C.P. 2013. Cyatheaceae. In: J. Prado \& L.S. Sylvestre (coords.). Samambaias e licófitas. In: R.C. Forzza, J.F. Baumgratz, C.E. de M. Bicudo, D. Canhos, A.A. Carvalho Jr., A. Costa, D.P. Costa, M. Hopkins, M.P. Leitman, L.G. Lohmann, E.N. Lughadha, L.C. Maia, G. Martinelli, M. Menezes, M.P. Morin, M. Nadruz, A.L. Peixoto, J.R. Pirani, J. Prado, L.P. Queiroz, S. de Souza, V.C. Souza, J.R. Stehmann, L.S. Sylvestre, B.M.T. Walter \& D.C. Zappi (eds.). Lista de Espécies da Flora do Brasil. Disponível em http:// floradobrasil.jbrj.gov.br/jabot/floradobrasil/FB90887 (acesso em 28-VII-2013). 